\title{
Ventral Tegmental Dopamine Dysregulation Prevents Appetitive Memory Destabilization
}

\author{
Amy C. Reichelt, Marc T. Exton-McGuinness, and Jonathan L.C. Lee \\ School of Psychology, University of Birmingham, Birmingham, B15 2TT, United Kingdom
}

Through the process of reconsolidation, memories can be updated to maintain their relevance. To reconsolidate, a memory must first be destabilized in a process that we have hypothesized is initiated by a prediction error signal. Here we demonstrate that dysregulation of ventral tegmental area (VTA) signaling, which is thought to mediate prediction errors, prevented the destabilization of an appetitive goal-tracking memory in rats. We additionally show that intra-VTA infusion of either the competitive NMDA antagonist AP5 or the noncompetitive NMDA antagonist MK-801 does not selectively disrupt reconsolidation, indicating that the VTA may not be an important neural locus of reconsolidation-related neural plasticity.

\section{Introduction}

The updating of long-term memories is essential to maintain their relevance in day-to-day life. The mechanism by which memories are updated has been linked to the process of memory reconsolidation (Lee, 2009). The retrieval of memories can lead to their destabilization, requiring a restabilization process that is known as reconsolidation (Alberini, 2005; Nader and Hardt, 2009). Reconsolidation appears to occur specifically under conditions that enable memory updating. Therefore, the plasticity involved in reconsolidation may enable the integration of updating information (Lee, 2009). Given that trial-by-trial learning is a form of memory updating and that it is conceptually linked to prediction error signals, we hypothesized that prediction error is a prerequisite for memory destabilization and reconsolidation (Lee, 2009). Although hypothesized prediction errors have been closely linked to memory destabilization (Sevenster et al., 2013), it has yet to be demonstrated that prediction error signals are necessary for memory destabilization. Therefore, we tested the hypothesis that dysregulation of prediction error signals would prevent memory destabilization.

We have recently demonstrated that memory reconsolidation is disrupted by systemic injections of the NMDA receptor antagonist (+)-5-methyl-10,11-dihydro-5H-dibenzo[ $a, d]$ cyclohepten-5,10-imine maleate (MK-801) in a Pavlovian-conditioned approach setting (Reichelt and Lee, 2012; but see Blaiss and Janak, 2009). Moreover, in a similar setting, prediction error sig-

\footnotetext{
Received April 16, 2013; revised June 19, 2013; accepted July 26, 2013.

Author contributions: A.C.R. and J.L.C.L. designed research; A.C.R., M.T.E.M., and J.L.C.L. performed research; A.C.R. and J.L.C.L. analyzed data; A.C.R. and J.L.C.L. wrote the paper.

This study was supported by the Leverhulme Trust Grant F/00 094/BK to J.L.C.L. We thank David Barber for his assistance with data collection and histology.

The authors declare no competing financial interests.

Correspondence should be addressed to Dr. Amy C. Reichelt, School of Medical Sciences, University of New South Wales, Kensington, Sydney, NSW 2052, Australia. E-mail: a.reichelt@unsw.edu.au.

A.C. Reichelt's present address: School of Medical Sciences, University of New South Wales, Kensington, Sydney, NSW 2052, Australia.

DOI:10.1523/JNEUROSCI.1614-13.2013

Copyright $\odot 2013$ the authors $\quad 0270-6474 / 13 / 3314205-06 \$ 15.00 / 0$
}

naling is critically dependent upon ventral tegmental area (VTA) dopaminergic activity (Takahashi et al., 2009). This prediction error is governed by phasic dopamine signaling originating within the midbrain and is bidirectional in nature (Waelti et al., 2001). This indicates that the unexpected omission of a reward or delivery of a reward of a lesser value is demonstrated to generate a negative prediction error signal (Hollerman and Schultz, 1998; Takahashi et al., 2009). Given that MK-801 impairs reconsolidation under the same behavioral conditions of overexpectation (Reichelt and Lee, 2013), it can be hypothesized that prediction error signals are necessary to destabilize memories so that they can be updated. Therefore, we tested the hypothesis that dysregulation of VTA dopaminergic signaling would impair the putative prediction error signal induced by memory retrieval to prevent goal-tracking memories from being destabilized. As a result, those memories would be resistant to the amnestic effect of MK801 (Ben Mamou et al., 2006). In Experiment 1a, microinfusions of the GABA agonists baclofen and muscimol, the dopamine $\mathrm{D}_{2}$ antagonist sulpiride, or PBS (control), were made before memory reactivation to dysregulate the VTA and to disrupt the putative negative prediction error signal. Rats were then administered systemic MK-801 or saline to disrupt memory reconsolidation as previously demonstrated by Reichelt and Lee (2012). In Experiment $1 \mathrm{~b}$, we tested the hypothesis that the VTA is not the locus of amnestic effect of systemically administered MK-801 and instead provides a critical signal to brain regions where this updating mechanism takes place.

\section{Materials and Methods}

Animals. Ninety-eight experimentally naive male Lister Hooded rats (Harlan) weighing between 260 and $290 \mathrm{~g}$ were used in the experiment. Rats were housed in groups of four on a $12 \mathrm{~h} \mathrm{light/dark} \mathrm{cycle.} \mathrm{Before} \mathrm{behavioral} \mathrm{train-}$ ing, rats were food restricted to $85-90 \%$ of their free feeding weights. All rats were handled before behavioral training. Behavioral training was performed between 8:00 A.M. and 11:00 A.M. each day. Animal husbandry and experimental procedures were conducted in compliance with the United Kingdom Animals (Scientific Procedures) Act 1986 (PPL 40/3205).

Surgery. Stainless steel guide cannulae (26G, Cooper's Needleworks) were implanted bilaterally in the VTA ( $5.4 \mathrm{~mm}$ posterior to bregma, 1.8 
$\mathrm{mm}$ lateral, and $7.3 \mathrm{~mm}$ vertical, angled at $10^{\circ}$ toward the midline from vertical).

Behavioral procedure. Pavlovian-conditioned approach training was performed in eight standard behavioral chambers (Med Associates), housed in sound attenuating boxes (see Reichelt and Lee, 2012). Rats were trained to respond to two discriminable auditory stimuli (click or tone; $\mathrm{CS}^{+}$and $\mathrm{CS}^{-} ; 10$ presentations of each per session; see Fig. $1 A$ ) for $6 \mathrm{~d}$ as previously described (Reichelt and Lee, 2012). Stimuli were presented for $30 \mathrm{~s}$, with $30 \mathrm{~s}$ Pre-CS and interstimulus periods. Discrimination performance was measured by response ratios calculated by magazine responding during CS presentation/(CS + Pre-CS responding). Thus, response ratios $>0.5$ indicate increased responding to the CS compared with baseline responding, whereas a ratio $=0.5$ indicates no difference from Pre-CS responding and therefore no discriminative performance. For the first $3 \mathrm{~d}$ of training, the $\mathrm{CS}^{+}$was reinforced with delivery of one sucrose pellet at the start of the CS and two pellets at the end of the CS; for days 4-6, three pellets were delivered at the termination of the $\mathrm{CS}^{+}$. After training, a short reactivation procedure took place, in which rats were exposed to three nonreinforced presentations of each CS. At test, rats were exposed to 10 nonreinforced presentations of each CS.

Drugs. In Experiment 1a, rats received bilateral microinfusions of 0.1 $\mathrm{mm}$ muscimol/1.0 mm baclofen (GABA $\mathrm{A} / \mathrm{B}_{\mathrm{B}}$ agonists, Sigma-Aldrich) at a volume of $0.15 \mu \mathrm{l}$ per site (Takahashi et al., 2009), $1 \mu \mathrm{g}$ sulpiride (dopamine $\mathrm{D}_{2}$ antagonist, Sigma-Aldrich) at a volume of $0.5 \mu \mathrm{l}$ per site (Nazari-Serenjeh et al., 2011), or sterile 0.9\% PBS (at equivalent volumes) to serve as a control infusion immediately before the reactivation session. Rats were administered MK-801 (Sigma-Aldrich), dissolved in $0.9 \%$ saline $(0.1 \mathrm{mg} / \mathrm{ml})$ at a dose of $0.1 \mathrm{mg} / \mathrm{kg}$ by intraperitoneal injection immediately after the reactivation procedure. Saline $(0.9 \%)$ served as vehicle control.

In Experiment 1b, rats were infused with $0.3 \mu \mathrm{g}$ AP5 (NMDA receptor antagonist, Sigma-Aldrich) at a volume of $0.3 \mu \mathrm{l}$ (Svensson et al., 1998), MK-801 at a volume of $0.3 \mu \mathrm{l}$ (Petralia et al., 2007), or $0.3 \mu \mathrm{l}$ sterile $0.9 \%$ PBS per site immediately before the reactivation session. No postreactivation injections were made. A test $24 \mathrm{~h}$ after reactivation was then performed as described in Experiment 1a.

Histology. After testing, rats were killed using $\mathrm{CO}_{2}$, and brains extracted and fixed in $4 \%$ PFA for histological verification of cannula placements. Coronal sections $(60 \mu \mathrm{m})$ were sliced on a vibratome and stained with cresyl violet. The brains were then verified for cannulae placement under a light microscope.

\section{Results}

Three rats failed to acquire the discriminations (responding more to the $\mathrm{CS}^{+}$than the $\mathrm{CS}^{-}$on the final day of training) and were excluded from data analyses. Nine rats did not complete the experiment because of ill health or loss of the headcap attaching the cannulae to the skull surface. Finally, six rats were excluded from analysis because of incorrect cannulae placements (for histological verification, see Fig. $1 B, C)$.

Test data were analyzed using repeated-measures ANOVAs with within factors of $\mathrm{CS}\left(\mathrm{CS}^{+}, \mathrm{CS}^{-}\right)$and between-subjects factor of drug (MK-801, saline) for each infusion group (PBS, muscimol and baclofen $[\mathrm{M} / \mathrm{B}]$, sulpiride) in Experiment 1a. In Experiment 1b, data were analyzed using repeated-measures ANOVAs with within factors of CS $\left(\mathrm{CS}^{+}, \mathrm{CS}^{-}\right)$and betweensubjects factor of infusion group (PBS, AP5, MK-801).

\section{Experiment 1a}

All groups had acquired the discriminations equally by the end of training (Table 1) (main effect of CS, $F_{(1,50)}=68.603, p<0.001$; main effect of drug, $F_{(5,50)}<1$; CS $\times$ drug interaction, $F_{(5,50)}=$ $1.011, p=0.421)$.

The VTA was dysregulated by infusions of M/B (Takahashi et al., 2009) or sulpiride. Infusions had no effect on discriminative performance during memory reactivation (Table 1) (main effect of CS, $F_{(1,50)}=27.182, p<0.001$; main effect of drug, $F_{(5,50)}<1$; $\mathrm{CS} \times$ drug interaction, $\left.F_{(5,50)}<1\right)$.

In control rats infused with PBS vehicle, postretrieval injection of MK-801 impaired reconsolidation to reduce discriminated responding to the stimulus previously associated with sucrose (Fig. 2A). Whereas saline-injected rats responded more to the $\mathrm{CS}^{+}$than the unpaired $\mathrm{CS}^{-}$, MK-801-injected rats showed no such preference. There was a significant MK-801 $\times$ CS interaction $\left(F_{(1,17)}=5.746, p=0.049\right)$, with a significant main effect of CS $\left(F_{(1,16)}=11.253, p=0.007\right)$, but no main effect of MK-801 $\left(F_{(1,17)}<1\right)$. Analysis of simple effects revealed a significant effect of CS in rats administered saline $\left(F_{(1,17)}=14.129, p=0.002\right)$, but not in rats administered MK-801 $\left(F_{(1,17)}<1\right)$. These results replicate our previous observation that MK- 801 impairs the reconsolidation of goal-tracking memories (Reichelt and Lee, 2012), with the difference that MK-801 was administered after the retrieval session in the present study, as opposed to $30 \mathrm{~min}$ before memory retrieval previously. Moreover, there appeared to be no nonspecific impact of VTA cannulation or vehicle infusion upon goal-tracking performance.

When $\mathrm{M} / \mathrm{B}$ was infused into the VTA before memory retrieval, postsession MK-801 was without effect on subsequent goal tracking (Fig. $2 B$ ). There was a significant main effect of CS $\left(F_{(1,16)}=\right.$ 27.967, $p=0.001)$, with no effect of MK-801 $\left(F_{(1,16)}<1\right)$ or MK-801 $\times$ CS interaction $\left(F_{(1,16)}<1\right)$. Therefore, both groups responded more to the $\mathrm{CS}^{+}$than to the $\mathrm{CS}^{-}$. Importantly, a direct comparison between the PBS- and M/B-infused rats revealed evidence that $\mathrm{M} / \mathrm{B}$ did indeed protect against the amnestic effect of MK-801. For those rats injected with MK-801, infusion of $\mathrm{M} / \mathrm{B}$ had a significant effect, revealed by a significant $\mathrm{M} / \mathrm{B} \times \mathrm{CS}$ interaction $\left(F_{(1,15)}=5.743, p=0.03\right)$, with a significant main effect of CS $\left(F_{(1,15)}=10.416, p=0.006\right)$, but not of $\mathrm{M} / \mathrm{B}\left(F_{(1,15)}=\right.$ $1.898, p=0.189)$. In contrast, there was no effect of $M / B$ infusion alone, as there were no differences between the groups injected with saline $\left(\mathrm{M} / \mathrm{B} \times \mathrm{CS}\right.$ interaction, $F_{(1,17)}<1$; main effect of $\mathrm{M} / \mathrm{B}, F_{(1,17)}=1.016, p=0.328$; main effect of CS, $F_{(1,17)}=$ $32.564, p<0.001)$. Therefore, infusion of $\mathrm{M} / \mathrm{B}$ into the VTA prevented the goal-tracking memory from destabilizing, thereby protecting it against the amnestic effect of MK- 801 .

This protective effect of M/B was replicated by infusions of sulpiride into the VTA (Fig. $2 C$ ). There was a significant main effect of CS $\left(F_{(1,16)}=44.144, p=0.001\right)$, with no effect of sulpiride $\left(F_{(1,16)}<1\right)$ or sulpiride $\times$ CS interaction $\left(F_{(1,16)}<\right.$ $1)$. Therefore, both sulpiride-infused groups responded more to the $\mathrm{CS}^{+}$than to the $\mathrm{CS}^{-}$. Again, a direct planned comparison between the PBS- and sulpiride-infused rats revealed evidence that sulpiride did protect against the amnestic effect of MK-801. For the rats injected with MK-801, infusion of sulpiride had a significant effect (sulpiride $\times$ CS interaction, $F_{(1,17)}=5.974, p=0.026$; main effect of sulpiride, $F_{(1,17)}<1$; main effect of CS, $\left.F_{(1,17)}=11.187, p=0.004\right)$. In contrast, there was no effect of sulpiride infusion alone, as there were no differences between the groups injected with saline (sulpiride $X$ CS interaction, $F_{(1,15)}<1$; main effect of sulpiride, $F_{(1,15)}<1$; main effect of CS, $\left.F_{(1,15)}=54.574, p=0.001\right)$. Therefore, infusion of sulpiride into the VTA also prevented the goal-tracking memory from destabilizing and, hence, protected it from the amnestic effect of MK-801.

The drug treatments had no effect on levels of responding overall, measured by magazine entries during the Pre-CS and CS (Table 2; main effect of drug, $F_{(5,50)}=1.202, p=0.321$; main effect of CS, $F_{(1,50)}=46.561, p<0.001 ; C S \times$ drug interaction, 

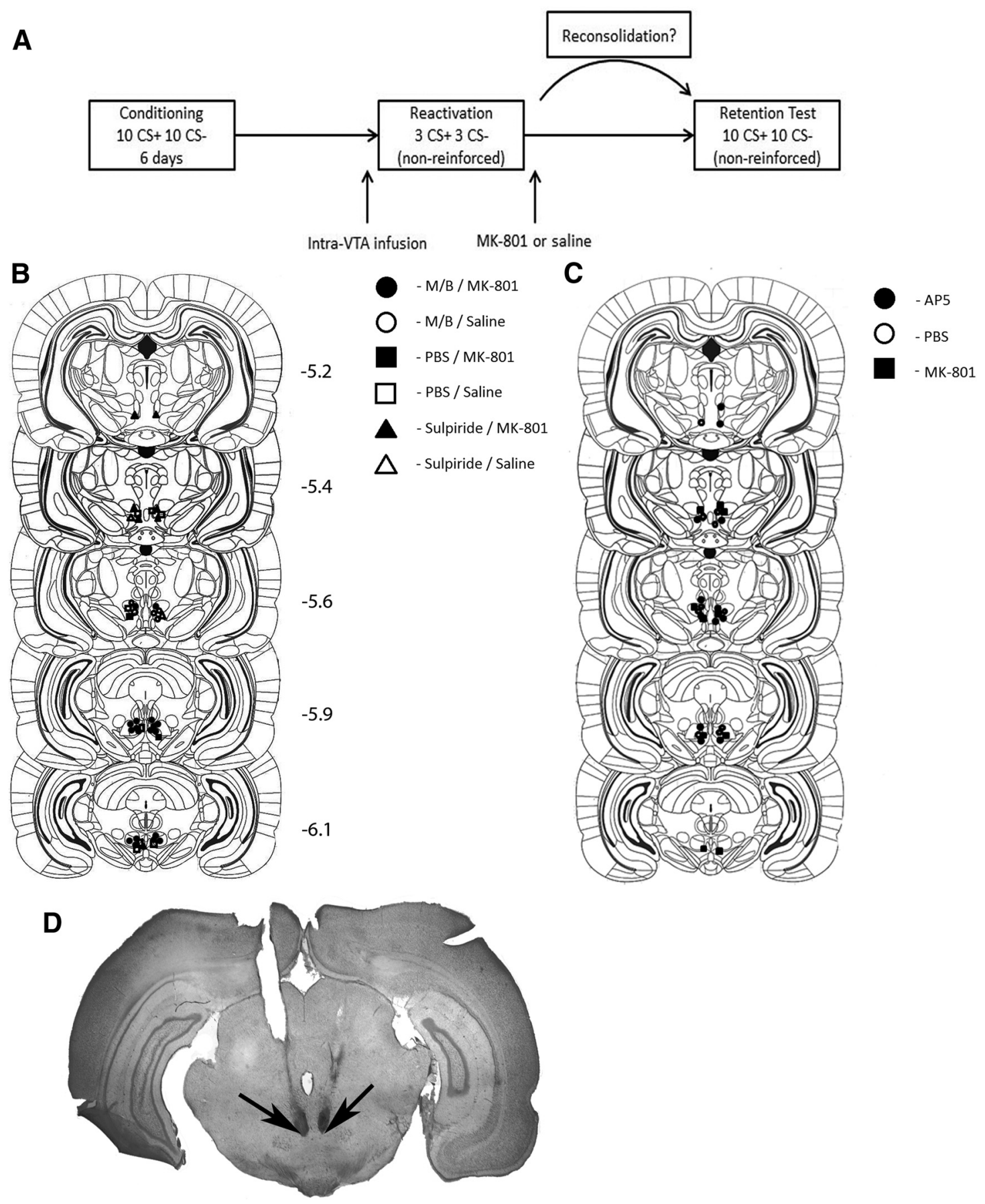

Figure 1. A, Experimental design. $\boldsymbol{B}$, Representation of cannulae placements in Experiment 1a (coronal sections; $\mathrm{mm}$ from bregma). $\boldsymbol{C}$, Cannulae placements in Experiment $1 \mathrm{~b}$. $\boldsymbol{D}$, Photomicrograph depicting cannula placements. Arrows indicate cannula tips.

$\left.F_{(5,50)}=2.73, p=0.029\right)$; demonstrating discriminative performance was disrupted in the PBS/MK-801 condition $\left(F_{(1,50)}<1\right)$ but not in other microinfusion conditions ( $F$ values $>4.172$ ).

\section{Experiment $1 \mathrm{~b}$}

Equal baseline responding was observed on the final day of training (Table 1), indicating that all groups had acquired the discriminations equally (main effect of CS, $F_{(1,20)}=40.387, p<0.001$; main effect of drug, $F_{(1,20)}<1$; CS $\times$ drug interaction, $\left.F_{(2,20)}<1\right)$.

Microinfusions did not affect discriminative performance during memory reactivation (Table 1) (main effect of CS,
$F_{(1,20)}=7.968, p<0.01$; main effect of drug, $F_{(1,20)}=1.459, p=$ 0.256 ; CS $\times$ drug interaction, $\left.F_{(2,20)}=1.01, p=0.382\right)$.

Importantly, the neuroanatomical locus of action of systemically applied MK-801 is highly unlikely to be the VTA (Fig. 2D), as intra-VTA infusions of AP5 or MK-801 did not replicate the effect of systemic injections of MK-801 (drug $\times$ CS interaction, $F_{(2,20)}<1$; main effect of drug, $F_{(2,20)}<1$; main effect of CS, $\left.F_{(1,20)}=17.99, p=0.001\right)$. This demonstrates that, although the locus of reconsolidation plasticity of the Pavlovian-conditioned approach memory remains to be determined, the control of its destabilization is regulated, at 
least in part, by activity in an anatomically distinct brain region.

\section{Discussion}

The present results show that infusion of $\mathrm{M} / \mathrm{B}$ or sulpiride into the VTA protects a reactivated goal-tracking memory from being disrupted by postreactivation injections of MK-801. The pharmacological protection of reactivation-dependent amnesia has been demonstrated previously (Ben Mamou et al., 2006) and has been interpreted as reflecting a prevention of memory destabilization. As the memory is not destabilized, it does not require reconsolidation and therefore is rendered resistant to the amnestic effect of protein synthesis inhibitors or, here, MK-801. Thus, our infusions into the VTA appear to impair goal-tracking memory destabilization.

Recently, Sevenster et al. (2013) have demonstrated that the reconsolidation of human fear memories only takes place when the reactivation session induces a putative prediction error signal, independently verified by a mismatch between subjective expectancy ratings and the actual occurrence of the outcome. Therefore, administration of the $\beta$-adrenergic antagonist propranolol had no effect on subsequent postreactivation measures of fear when retrieval was not seemingly sufficient to generate a prediction error. However, this does not by itself demonstrate that the occurrence of putative prediction error signals, such as those established in the nonhuman literature to be elicited in midbrain dopaminergic neurons for appetitive Pavlovian conditioning (Valentin and O'Doherty, 2009), is necessary for the destabilization of memories. Despite the cross-species and cross-paradigm comparisons, the combination of the previous work by Sevenster et al. (2013) and our current results strongly suggests that prediction error signals are truly necessary for memory destabilization and the induction of reconsolidation. Indeed, another recent study of rat fear conditioning lends further support to the necessity for error signaling in triggering memory reconsolidation. Diaz-Mataix et al. (2013) focused on the temporal occurrence of the aversive footshock outcome, showing that the unpredictable timing of the footshock at memory reactivation was closely associated with the induction of memory reconsolidation.

The link between prediction error signals and reconsolidation is also supported by a number of studies in appetitive goal tracking. Using a Pavlovian overexpectation procedure that elicits negative prediction errors, Takahashi et al. (2009) demonstrated that the same M/B infusions as used in the present study impaired error-driven memory updating. We used a very similar procedure to show that Pavlovian overexpectation triggers memory reconsolidation, which we interpreted as mediating the errordriven memory updating (Reichelt and Lee, 2013), suggesting a relationship between functional prediction error signals and memory reconsolidation. As the extinction procedure in the present study is similarly hypothesized to elicit negative prediction error signals (Rescorla, 2003), and reconsolidation in both
Table 1. Discriminative performance on the final day of training (baseline) and during reactivation in each drug group in Experiments $1 \mathrm{a}$ and $1 \mathrm{~b}^{a}$

\begin{tabular}{|c|c|c|c|c|}
\hline \multirow[b]{2}{*}{ Infusion/drug } & \multicolumn{2}{|l|}{ Baseline } & \multicolumn{2}{|c|}{ Memory reactivation } \\
\hline & $\mathrm{CS}^{+}$ & $\mathrm{CS}^{-}$ & $\mathrm{CS}^{+}$ & $\mathrm{CS}^{-}$ \\
\hline PBS/saline & $0.75(0.03)$ & $0.53(0.05)$ & $0.79(0.04)$ & $0.56(0.06)$ \\
\hline PBS/MK-801 & $0.75(0.03)$ & $0.59(0.05)$ & $0.66(0.08)$ & $0.45(0.12)$ \\
\hline MB/saline & $0.77(0.03)$ & $0.46(0.05)$ & $0.81(0.04)$ & $0.54(0.07)$ \\
\hline MB/MK-801 & $0.72(0.04)$ & $0.53(0.07)$ & $0.73(0.07)$ & $0.53(0.09)$ \\
\hline Sulpiride/saline & $0.74(0.04)$ & $0.58(0.05)$ & $0.71(0.08)$ & $0.45(0.10)$ \\
\hline Sulpiride/MK-801 & $0.77(0.04)$ & $0.52(0.07)$ & $0.77(0.10)$ & $0.41(0.13)$ \\
\hline PBS & $0.76(0.03)$ & $0.53(0.05)$ & $0.76(0.05)$ & $0.34(0.09)$ \\
\hline MK-801 & $0.79(0.02)$ & $0.55(0.06)$ & $0.71(0.15)$ & $0.54(0.07)$ \\
\hline AP5 & $0.78(0.04)$ & $0.56(0.06)$ & $0.78(0.07)$ & $0.56(0.10)$ \\
\hline
\end{tabular}

${ }^{a}$ Data are mean (SEM).

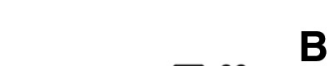
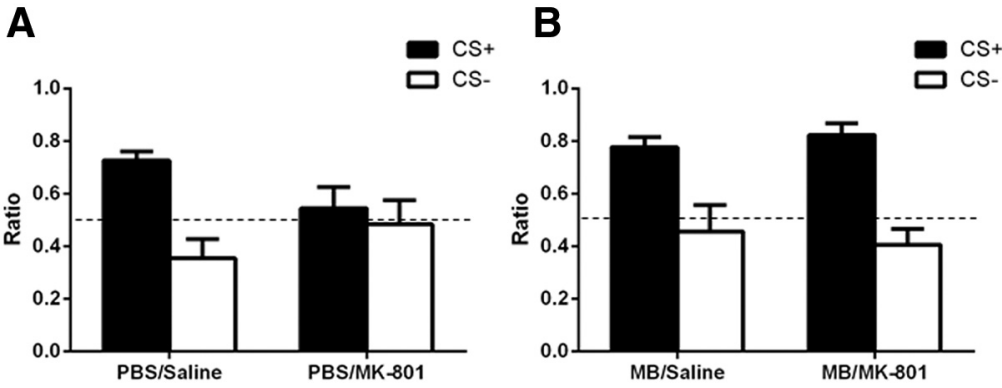

D

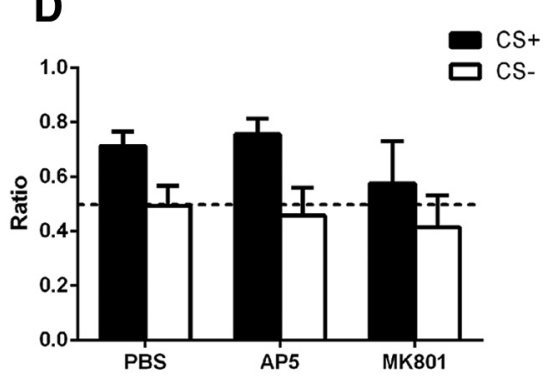

Figure 2. $\quad \boldsymbol{A}$, In PBS-infused controls, MK-801 impaired reconsolidation to abolish discriminated approach (PBS/saline, $N=11$; PBS/MK-801, $N=9$ ). $B$, Infusion of M/B protected against the amnestic effect of MK-801 (MB/saline, $N=11 ; M B / M K-801, N=$ 9). C, Infusion of sulpiride replicated the effect of $M / B$ (sulpiride/saline, $N=8$; sulpiride/MK-801, $N=10$ ). $\boldsymbol{D}$, Infusion of $A P 5$ or MK-801 into the VTA did not disrupt memory reconsolidation (PBS, $N=9 ; A P 5, N=9 ; M K-801, N=6)$. Data are mean $\pm S E M$. Dashed line indicates a discrimination ratio of 0.5 (no CS-induced alteration in responding).

Table 2. Raw responding to the magazine port during CS presentations and Pre-CS at test in each drug group ${ }^{a}$

\begin{tabular}{|c|c|c|c|c|}
\hline \multirow[b]{2}{*}{ Infusion/drug } & \multicolumn{2}{|l|}{$\mathrm{CS}^{+}$} & \multicolumn{2}{|l|}{$\mathrm{CS}^{-}$} \\
\hline & $C S$ & Pre-CS & CS & Pre-CS \\
\hline PBS/saline & $38.8(4.8)$ & $15.2(2.1)$ & $15.2(2.1)$ & $10.1(2.6)$ \\
\hline PBS/MK-801 & $15.1(3.1)$ & $10.2(2.2)$ & $7.4(1.8)$ & $11.3(3.5)$ \\
\hline MB/saline & $49.5(6.6)$ & $14.9(3.1)$ & $6.6(1.7)$ & $10.9(2.6)$ \\
\hline MB/MK-801 & $43.0(10.6)$ & $10.3(2.7)$ & $14.9(3.5)$ & $19.3(3.3)$ \\
\hline Sulpiride/saline & $51.9(11.7)$ & $12.5(4.3)$ & $8.4(2.4)$ & $16.4(5.2)$ \\
\hline Sulpiride/MK-801 & $37.4(12.5)$ & $10.7(4.8)$ & $16.5(5.3)$ & $11.6(3.4)$ \\
\hline
\end{tabular}

the present goal-tracking task and the overexpectation paradigm are commonly impaired by MK-801 (Reichelt and Lee, 2012, 2013), the present demonstration that VTA dysregulation prevents memory destabilization and reconsolidation suggests that the effect of VTA dysregulation is the result of the disruption of negative prediction error signaling.

The common effect of $\mathrm{M} / \mathrm{B}$, as GABA receptor agonists, and sulpiride, as a $\mathrm{D}_{2}$ dopaminergic receptor antagonist, is most likely 
the result of dysregulation of VTA dopaminergic efferents that code for prediction error signals. The use of $\mathrm{M} / \mathrm{B}$, and its resultant inhibition of the VTA, has previously been argued to impair the phasic suppression of DA neuronal firing that is hypothesized to regulate learning in response to negative prediction errors (Hollerman and Schultz, 1998; Takahashi et al., 2009). The memory retrieval in the current study occurs in extinction and, hence, would be similarly hypothesized to induce a negative prediction error signal that is thought to be necessary to drive reconsolidation-mediated memory updating. Therefore, it is also of note that infusion of sulpiride into the VTA results in the same qualitative outcome. Intra-VTA infusion of sulpiride has been demonstrated to result in the activation of inhibitory $\mathrm{D}_{2}$ autoreceptors, thus increasing tonic dopamine release in the nucleus accumbens (Westerink et al., 1996). It could be expected that such a tonic increase would enhance the signal-to-noise ratio of a phasic decrease, thereby potentiating the prediction error signal. However, the present results suggest that the tonic increase instead, by some mechanism, masks the phasic suppression of DA firing that characterizes the prediction error signal. It should be noted that the use of manipulations that alter tonic dopaminergic activity only indirectly implicates phasic dopaminergic signals in appetitive memory destabilization. Optogenetic techniques have recently been used to induce phasic dopaminergic signals in the VTA, thereby providing direct functional evidence for the involvement of these signals in learning using extinction and blocking paradigms (Steinberg et al., 2013). Such an experimental approach would be predicted also to enable memory destabilization under behavioral (boundary) conditions that do not normally engage reconsolidation.

In our previous study of memory reconsolidation in the goaltracking setting, we revealed discrete boundary conditions on memory reconsolidation (Reichelt and Lee, 2012). Insufficient stimulus reexposure relative to the strength of training did not result in MK-801-induced reconsolidation impairment. In contrast, excessive stimulus reexposure resulted in extinction, rather than reconsolidation, being disrupted. Therefore, we can posit that memories may not undergo reconsolidation when the reactivation session does not sufficiently generate a prediction error capable of inducing destabilization. Moreover, the parametric conditions in the present study are known to engage reconsolidation, rather than extinction, and so the behavioral effects of MK-801 highly likely reflect impairments in reconsolidation, rather than enhancements in extinction (but see Lattal and Wood, 2013). Previously, we used prereactivation injections of MK-801 successfully to disrupt reconsolidation (Reichelt and Lee, 2012). However, in the present experiment, it was necessary to use postreactivation MK-801 injections. Given the experimental aim targeting of memory destabilization, we adopted the rationale originally used by Ben Mamou et al. (2006) with the putative destabilization inhibitor administered before memory reactivation and the reconsolidation inhibitor administered postreactivation. Indeed, MK-801 has been used successfully to impair memory reconsolidation with postreactivation injections in other experimental settings (Lee and Everitt, 2008; Charlier and Tirelli, 2011).

Importantly, we also demonstrated that direct intra-VTA infusion of MK-801 or the alternative NMDA receptor antagonist AP5 did not replicate the systemic effect of MK-801 on memory reconsolidation. Intracerebral infusions of AP5 have previously been used to complement the systemic administration of MK801 , to inform the central locus of action of systemically applied NMDA receptor antagonists (Sakurai et al., 2007; Milton et al.,
2008), despite their differing modes of action. Therefore, the lack of amnestic effect of either drug strongly suggests that the VTA is likely not the central locus of action of the effect by systemically applied MK-801 to impair reconsolidation in the current study. Moreover, this means that reconsolidation is supported by the coordinated activity of a number of neural loci. Although it has been previously established that functional synaptic plasticity takes place in multiple neural loci to support appetitive memory reconsolidation (Milekic et al., 2006), there is little evidence suggesting that neural activity, but not synaptic plasticity, in one area regulates reconsolidation-related plasticity in a different region. Previous work has demonstrated a crucial role of the dorsal hippocampus in its contribution to reconsolidation in an appetitive setting. It has been shown that localized microinfusion of the sodium channel blocker TTX, but not the protein synthesis inhibitor anisomycin, administered into the dorsal hippocampus inhibited drug context-induced cocaine-seeking behavior in a memory reactivation-dependent manner (Ramirez et al., 2009). This study indicated TTX-sensitive mechanisms controlling neural activity within the dorsal hippocampus that are necessary for the reconsolidation of cocaine-related memories; however, the lack of anisomycin-impaired reconsolidation in this procedure suggests that the dorsal hippocampus facilitates reconsolidationrelated synaptic plasticity in other regions, such as the amygdala (Ramirez et al., 2009). In contrast, the present effects of VTA modulation on memory reconsolidation presented in these current studies are unique in showing that the regulation of memory destabilization in one neural locus (outside the VTA) is achieved by neural activity in a different area (VTA). We cannot exclude, however, the possibility that there is some functional plasticity in the VTA supporting goal tracking reconsolidation.

Although the VTA is not a likely important central locus of action of MK-801, there are several other candidate regions. For goal-tracking specifically, the nucleus accumbens core and central amygdala have been functionally implicated (Gallagher et al., 1990; Parkinson et al., 2000). Moreover, the basolateral amygdala and nucleus accumbens have been implicated in the cellular plasticity that underlies appetitive Pavlovian memory reconsolidation (Theberge et al., 2010), although there has yet to be any similar demonstration for the central amygdala. The focus on the amygdala and nucleus accumbens is of particular relevance as VTA dopaminergic neurons have strong efferent projections to these areas (Swanson, 1982). Therefore, it is likely that the regulation of the destabilization of goal-tracking memories is achieved by midbrain dopaminergic innervation of the amygdala and/or nucleus accumbens.

In conclusion, the functional regulation of memory destabilization and reconsolidation by prediction error signaling further reinforces the hypothesis that reconsolidation plays a critical role in memory updating, and indicates that reconsolidation may be a mechanistic component of certain theories of learning.

Note added in proof. It has been demonstrated recently that central nucleus plasticity is necessary for the reconsolidation of alcoholassociated memories (Barak et al., 2013).

\section{References}

Alberini CM (2005) Mechanisms of memory stabilization: are consolidation and reconsolidation similar or distinct processes? Trends Neurosci 28:51-56. CrossRef Medline

Barak S, Liu F, Ben Hamida S, Yowell QV, Neasta J, Kharazia V, Janak PH, Ron D (2013) Disruption of alcohol-related memories by mTORC1 inhibition prevents relapse. Nat Neurosci 16:1111-1117. CrossRef

Ben Mamou C, Gamache K, Nader K (2006) NMDA receptors are critical 
for unleashing consolidated auditory fear memories. Nat Neurosci 9:1237-1239. CrossRef Medline

Blaiss CA, Janak PH (2009) The nucleus accumbens core and shell are critical for the expression, but not the consolidation, of Pavlovian conditioned approach. Behav Brain Res 200:22-32. CrossRef Medline

Charlier Y, Tirelli E (2011) Differential effects of histamine H(3) receptor inverse agonist thioperamide, given alone or in combination with the $\mathrm{N}$-methyl-D-aspartate receptor antagonist dizocilpine, on reconsolidation and consolidation of a contextual fear memory in mice. Neuroscience 193:132-142. CrossRef Medline

Díaz-Mataix L, Ruiz Martinez RC, Schafe GE, LeDoux JE, Doyere V (2013) Detection of a temporal error triggers reconsolidation of amygdaladependent memories. Curr Biol 23:467-472. CrossRef Medline

Gallagher M, Graham PW, Holland PC (1990) The amygdala central nucleus and appetitive Pavlovian conditioning: lesions impair one class of conditioned behavior. J Neurosci 10:1906-1911. Medline

Hollerman JR, Schultz W (1998) Dopamine neurons report an error in the temporal prediction of reward during learning. Nat Neurosci 1:304-309. CrossRef Medline

Lattal KM, Wood MA (2013) Epigenetics and persistent memory: implications for reconsolidation and silent extinction beyond the zero. Nat Neurosci 16:124-129. CrossRef Medline

Lee JL (2009) Reconsolidation: maintaining memory relevance. Trends Neurosci 32:413-420. CrossRef Medline

Lee JL, Everitt BJ (2008) Appetitive memory reconsolidation depends upon NMDA receptor-mediated neurotransmission. Neurobiol Learn Mem 90:147-154. CrossRef Medline

Milekic MH, Brown SD, Castellini C, Alberini CM (2006) Persistent disruption of an established morphine conditioned place preference. J Neurosci 26:3010-3020. CrossRef Medline

Milton AL, Lee JL, Everitt BJ (2008) Reconsolidation of appetitive memories for both natural and drug reinforcement is dependent on $\beta$-adrenergic receptors. Learn Mem 15:88-92. CrossRef Medline

Nader K, Hardt O (2009) A single standard for memory: the case for reconsolidation. Nat Rev Neurosci 10:224-234. CrossRef Medline

Nazari-Serenjeh F, Rezayof A, Zarrindast MR (2011) Functional correlation between GABAergic and dopaminergic systems of dorsal hippocampus and ventral tegmental area in passive avoidance learning in rats. Neuroscience 196:104-114. CrossRef Medline

Parkinson JA, Willoughby PJ, Robbins TW, Everitt BJ (2000) Disconnection of the anterior cingulate cortex and nucleus accumbens core impairs Pavlovian approach behavior: further evidence for limbic cortical-ventral striatopallidal systems. Behav Neurosci 114:42-63. CrossRef Medline

Petralia SM, DeBold JF, Frye CA (2007) MK-801 infusions to the ventral tegmental area and ventromedial hypothalamus produce opposite effects on lordosis of hormone-primed rats. Pharmacol Biochem Behav 86:377385. CrossRef Medline
Ramirez DR, Bell GH, Lasseter HC, Xie X, Traina SA, Fuchs RA (2009) Dorsal hippocampal regulation of memory reconsolidation processes that facilitate drug context-induced cocaine-seeking behavior in rats. Eur J Neurosci 30:901-912. CrossRef Medline

Reichelt AC, Lee JL (2012) Appetitive Pavlovian goal-tracking memories reconsolidate only under specific conditions. Learn Mem 20:51-60. CrossRef Medline

Reichelt AC, Lee JL (2013) Over-expectation generated in a complex appetitive goal-tracking task is capable of inducing memory reconsolidation. Psychopharmacology 226:649-658. CrossRef Medline

Rescorla RA (2003) Protection from extinction. Learn Behav 31:124-132. CrossRef Medline

Sakurai S, Yu L, Tan SE (2007) Roles of hippocampal N-methyl-D-aspartate receptors and calcium/calmodulin-dependent protein kinase II in amphetamine-produced conditioned place preference in rats. Behav Pharmacol 18:497-506. CrossRef Medline

Sevenster D, Beckers T, Kindt M (2013) Prediction error governs pharmacologically induced amnesia for learned fear. Science 339:830-833. CrossRef Medline

Steinberg EE, Keiflin R, Boivin JR, Witten IB, Deisseroth K, Janak PH (2013) A causal link between prediction errors, dopamine neurons and learning. Nat Neurosci 16:966-973. CrossRef Medline

Svensson TH, Mathé JM, Nomikos GG, Schilström B (1998) Role of excitatory amino acids in the ventral tegmental area for central actions of non-competitive NMDA-receptor antagonists and nicotine. Amino Acids 14:51-56. CrossRef Medline

Swanson LW (1982) The projections of the ventral tegmental area and adjacent regions: a combined fluorescent retrograde tracer and immunofluorescence study in the rat. Brain Res Bull 9:321-353. CrossRef Medline

Takahashi YK, Roesch MR, Stalnaker TA, Haney RZ, Calu DJ, Taylor AR, Burke KA, Schoenbaum G (2009) The orbitofrontal cortex and ventral tegmental area are necessary for learning from unexpected outcomes. Neuron 62:269-280. CrossRef Medline

Théberge FR, Milton AL, Belin D, Lee JL, Everitt BJ (2010) The basolateral amygdala and nucleus accumbens core mediate dissociable aspects of drug memory reconsolidation. Learn Mem 17:444-453. CrossRef Medline

Valentin VV, O’Doherty JP (2009) Overlapping prediction errors in dorsal striatum during instrumental learning with juice and money reward in the human brain. J Neurophysiol 102:3384-3391. CrossRef Medline

Waelti P, Dickinson A, Schultz W (2001) Dopamine responses comply with basic assumptions of formal learning theory. Nature 412:43-48. CrossRef Medline

Westerink BH, Kwint HF, deVries JB (1996) The pharmacology of mesolimbic dopamine neurons: a dual-probe microdialysis study in the ventral tegmental area and nucleus accumbens of the rat brain. J Neurosci 16:2605-2611. Medline 